\title{
Noninvasive detection of macrophages in atherosclerotic lesions by computed tomography enhanced with PEGylated gold nanoparticles
}

This article was published in the following Dove Press journal:

International Journal of Nanomedicine

2 December 2014

Number of times this article has been viewed

\author{
Jinbao Qin ${ }^{1, *}$ \\ Chen Peng ${ }^{2, *}$ \\ Binghui Zhao ${ }^{2, *}$ \\ Kaichuang $\mathrm{Ye}^{\prime}$ \\ Fukang Yuan' \\ Zhiyou Peng' \\ Xinrui Yang' \\ Lijia Huang' \\ Mier Jiang' \\ Qinghua Zhao ${ }^{3}$ \\ Guangyu Tang ${ }^{2}$ \\ Xinwu Lu ${ }^{1,4}$
}

'Department of Vascular Surgery, Shanghai Ninth People's Hospital Affiliated to Shanghai JiaoTong University, School of Medicine; ${ }^{2}$ Department of Radiology, Shanghai Tenth People's Hospital Affiliated to Tongji University, School of Medicine; ${ }^{3}$ Department of Orthopaedics, Shanghai First People's Hospital, School of Medicine, Shanghai Jiao Tong University; ${ }^{4}$ Vascular Center of Shanghai JiaoTong University, Shanghai, People's Republic of China

*These authors contributed equally to this work
Correspondence: Xinwu Lu Email luxinwu@aliyun.com

Guangyu Tang

Email tgy17@|26.com

Qinghua Zhao

Email sawboneszhao@I63.com

\begin{abstract}
Macrophages are becoming increasingly significant in the progression of atherosclerosis (AS). Molecular imaging of macrophages may improve the detection and characterization of AS. In this study, dendrimer-entrapped gold nanoparticles (Au DENPs) with polyethylene glycol (PEG) and fluorescein isothiocyanate (FI) coatings were designed, tested, and applied as contrast agents for the enhanced computed tomography (CT) imaging of macrophages in atherosclerotic lesions. Cell counting kit- 8 assay, fluorescence microscopy, silver staining, and transmission electron microscopy revealed that the FI-functionalized Au DENPs are noncytotoxic at high concentrations $(3.0 \mu \mathrm{M})$ and can be efficiently taken up by murine macrophages in vitro. These nanoparticles were administered to apolipoprotein $\mathrm{E}$ knockout mice as AS models, which demonstrated that the macrophage burden in atherosclerotic areas can be tracked noninvasively and dynamically three-dimensionally in live animals using micro-CT. Our findings suggest that the designed PEGylated gold nanoparticles are promising biocompatible nanoprobes for the CT imaging of macrophages in atherosclerotic lesions and will provide new insights into the pathophysiology of AS and other concerned inflammatory diseases.
\end{abstract}

Keywords: atherosclerosis, CT, in vivo imaging

\section{Introduction}

Cardiovascular and cerebrovascular diseases, especially those caused by atherosclerosis (AS), are the main causes of death in aging societies. ${ }^{1,2}$ Substantial evidence demonstrates that AS is a diffused disease, which is characterized by endothelial injury, cholesterol deposition, and inflammation in lumen. ${ }^{3,4}$ In AS progression, monocytes derived from the blood or bone marrow migrate into endothelial injury sites and differentiate into macrophages, which secrete a variety of inflammatory cytokines, stimulating smooth muscle cell proliferation, migration, and extracellular matrix remolding. ${ }^{5,6} \mathrm{~A}$ high macrophage content is one of the main factors associated with an elevated risk of atherosclerotic lesions (eg, unstable plaque rupture and thrombosis), thus, macrophages are one of the most promising therapeutic targets for treating AS. ${ }^{7,8}$ Therefore, developing an effective noninvasive method for the early detection of macrophage content may improve diagnosis and characterization of AS, and will likely provide new insights into the pathophysiology of AS.

Molecular imaging profoundly influences preclinical research and future clinical cardiovascular medicine in many ways, such as in the early diagnosis and assessment of chronic diseases. ${ }^{9-11}$ Promising molecular imaging instruments such as computed tomography (CT) have high spatial and high density resolutions, which have great potential for the risk-stratified detection of atherosclerotic lesions and may be used

submit your manuscript $\mid$ www.dovepress.con 
to identify patients at higher risk of acute cardiovascular events. ${ }^{12,13}$ However, to improve the diagnostic efficiency and accuracy of CT imaging, contrast agents are usually prerequisite to enhance the density and resolution of the target sites. ${ }^{14,15}$ The commercially available clinical CT imaging contrast agents are iodine-based agents (eg, iohexol) that have several drawbacks, including low k-edge energy, renal toxicity, high internal scattering, short imaging time, and lack of specificity. ${ }^{16,17}$ Sophisticated contrast agents need to be synthesized, characterized, and applied for molecular CT imaging to resolve these limitations.

Gold nanoparticles (AuNPs), one of the most promising sophisticated contrast agents, have drawn more attention over the past few years because of their stability, low toxicity, and high X-ray attenuation coefficients. ${ }^{18,19}$ Furthermore, AuNPs are relatively small, allowing them to easily cross the reticuloendothelial system to penetrate the underlying tissues, which provides them a much longer half-life in blood circulation than conventional iodine-based imaging agents $^{20,21}$ and facilitates their uptake by macrophages in AS. Previous studies have shown that AuNPs synthesized using fifth generation amine-terminated poly(amidoamine) (PAMAM) dendrimers or G5. $\mathrm{NH}_{2}$ can be acetylated for in vivo CT imaging of murine vessels. ${ }^{14,17,22}$ The excellent imaging capabilities of dendrimer-entrapped gold nanoparticles (Au DENPs) indicate that these nanoparticles (NPs) can also be used for CT imaging of macrophages in atherosclerotic lesions in vitro and in vivo.

In the present study, Au DENPs modified with polyethylene glycol (PEG) and fluorescein isothiocyanate (FI) were synthesized, characterized, and tested for murine macrophage uptake in vitro. Furthermore, the biocompatibility and cytotoxicity of Au DENPs were evaluated for cell viability using a cell counting kit-8 (CCK8) assay, cell cycle progression and apoptosis through flow cytometric analysis, and macrophagespecific markers through an immunofluorescence assay. The macrophage uptake of Au DENPs was investigated by silver staining, fluorescence microscopy, and transmission electron microscopy (TEM). Subsequently, the in vivo kinetics and biodistribution of Au DENPs in the blood pool and in macrophage-rich tissues were evaluated through micro-CT after intravenous injection in an apolipoprotein E knockout mice (ApoE-KO) AS model. Normally, the AS models are detected by magnetic resonance imaging in clinical diagnosis. To our knowledge, this is the first report related to the development of multifunctional Au DENPs modified with PEG to diagnose ApoE-KO mice with AS models for in vitro and in vivo $\mathrm{CT}$ imaging.

\section{Materials and methods Synthesis and characterization of FI-labeled PEGylated Au DENPs}

FI-labeled PEGylated Au DENPs were designed and tested as described in our previous work. ${ }^{17,23} \mathrm{mPEG}$ PAL (Shanghai Yanyi Biotechnology Corporation, Shanghai, People's Republic of China) dissolved in dimethyl sulfoxide (DMSO; Sigma-Aldrich Co., St Louis, MO, USA) were added into G5. $\mathrm{NH}_{2}$ dendrimer solution (Dendritech, Inc., Midland, MI, USA) in DMSO with vigorous magnetic stirring. The mixture was stirred continuously for 3 days to complete the reaction. FI in DMSO was subsequently added dropwise to the reaction solution, which was allowed to react for another day $\left(\mathrm{G} 5 . \mathrm{NH}_{2}: m\right.$ PEG-MAL:FI mole ratio of 1:20:5). The reaction mixture was extensively dialyzed thrice against $4 \mathrm{~L}$ of phosphate-buffered solution (PBS) and thrice against $4 \mathrm{~L}$ of water for 3 days to remove the excess reactants and byproducts, and then lyophilized to obtain the G5. $\mathrm{NH}_{2}$-FI- $m$ PEG.

The synthesis of $\left[\left(\mathrm{Au}^{0}\right)_{300}\right.$-G5.NHAc-FI- $m$ PEG] DENPs was adopted from a previous report. ${ }^{17} \mathrm{HAuCl}_{4}$ solution $(2 \mathrm{~mL}$ in water/methanol [volume per volume $=2: 1$ ]) was added into an aqueous G5.NH - -FI- $m$ PEG solution $(20 \mathrm{mg}, 10 \mathrm{~mL}$ ) under vigorous stirring. Thirty minutes later, ice-cold $\mathrm{NaBH}_{4}$ solution $(1 \mathrm{~mL}$, water/methanol [volume per volume $=2: 1$ ]) with more than four times the molar amount of Au salt was added to the gold salt/dendrimer mixture under stirring, and the stirring process was continued for 2 hours to complete the reaction. Subsequently, triethylamine (more than five times the molar amount of G5 PAMAM) was added to the mixture under magnetic stirring. Thirty minutes later, acetic anhydride $(31.0 \mu \mathrm{L}, 324 \mathrm{~mm}$, more than four times the molar amounts of the G5 PAMAM total primary amines) was added into the mixture solution; after that, the mixture was reacted for 24 hours. After being dialyzed and washed three times by PBS, we got the $\left[\left(\mathrm{Au}^{0}\right)_{300}\right.$-G5.NHAc-FI$m$ PEG] DENPs.

\section{Characterization techniques}

Ultraviolet-visible (UV-vis) spectra were recorded using a Lambda 25 UV/Vis spectrometer (PerkinElmer Inc., Waltham, MA, USA). The samples were dissolved in water before the experiments. TEM was performed using a JEOL 2010F analytical electron microscope (JEOL, Tokyo, Japan) operating at $200 \mathrm{kV}$. Aqueous FI-labeled PEGylated Au DENP solution $(1 \mathrm{mg} / \mathrm{mL})$ was dropped onto a carboncoated copper grid and air-dried before the measurements. The size distribution histogram of the FI-labeled PEGylated 
$\mathrm{Au}$ DENPs was measured using ImageJ software. For each sample, 300 NPs from different TEM micrographs were randomly selected to analyze their size.

\section{Cytotoxicity assay of Fl-labeled PEGylated Au DENPs}

The Ana-1 murine macrophages (Shanghai Cell Bank of the Chinese Academy of Sciences, Shanghai, People's Republic of China) were cultured in Roswell Park Memorial Institute (RPMI) 1640 medium (Gibco, Gaithersburg, MD, USA) with $10 \%$ fetal bovine serum (FBS) and 1\% streptomycin/ penicillin at $37^{\circ} \mathrm{C}$ under a humidified $5 \% \mathrm{CO}_{2}$ atmosphere. To quantify the cell viability under different PEGylated $\mathrm{Au}$ DENP concentrations, a Dojindo Laboratories' CCK-8 test (Kumamoto, Japan) was used. Ana- 1 cells at $1 \times 10^{4}$ cells/ well were cultured for 24 hours, then new medium containing FI-labeled PEGylated Au DENPs with different $\mathrm{Au}$ concentrations $(0,100,200,300$, and $400 \mu \mathrm{M})$ was added. After 24 hours of incubation, $10 \mu \mathrm{L}$ of CCK-8 in $100 \mu \mathrm{L}$ RPMI 1640 medium was added and incubated for 2 hours. Absorbance was analyzed at $450 \mathrm{~nm}$.

\section{Cellular uptake of FI-labeled PEGylated Au DENPs}

The macrophage uptake of FI-labeled PEGylated Au DENPs was verified by several methods, including silver staining, fluorescence microscopy, and TEM according to the manufacturer's protocols as we previous reported. ${ }^{15,17}$

For silver staining experiments, the Ana-1 cells were seeded $\left(1 \times 10^{6} /\right.$ well $)$ for 24 hours and treated with different Au concentrations $(0,100$, and $300 \mu \mathrm{M})$ for 4 hours. After washing, the cells were fixed and stained with silver reagents. Then the cells were washed thrice with double distilled water and stained with $1 \%$ nuclear fast red to stain their nuclei. After washing, they were observed under a light microscope (Olympus Corporation, Tokyo, Japan).

Fluorescence microscopic analysis was performed according to previously established methods using a fluorescence microscope (Nikon Corporation, Tokyo, Japan). ${ }^{24}$ Ana-1 cells were seeded at $1 \times 10^{6}$ cells/well for 24 hours and treated with medium containing FI-labeled PEGylated Au DENPs with different $\mathrm{Au}$ concentrations (0, 100, 200, 300, and $400 \mu \mathrm{M})$. After 24 hours of incubation, the macrophages were fixed with 4\% paraformaldehyde (PFA) for 20 minutes and washed thrice with PBS. After being treated in $0.3 \%$ Triton-X 100, the cells were then blocked with $10 \%$ goat serum at $37^{\circ} \mathrm{C}$ for 30 minutes. The cells were incubated overnight with F4/80 antibodies (rat anti-mouse, 1:500;
Abcam, Cambridge, UK) at $4{ }^{\circ} \mathrm{C}$ and secondary Alexa Fluor $^{\circledR} 555$ antibodies (goat anti-rat, 1:500; Thermo Fisher Scientific, Waltham, MA, USA). The nuclei were counterstained with 4',6-diamidino-2-phenylindole (DAPI, 1:500; Dako Denmark A/S, Glostrup, Denmark) using a standard procedure. Sample cells were recorded with a fluorescence microscope (Olympus Corporation).

For TEM imaging of the cellular internalization of the FI-labeled PEGylated Au DENPs, Ana-1 cells were seeded at $3 \times 10^{6}$ in $25 \mathrm{~cm}^{2}$ culture flasks for 24 hours and incubated with FI-labeled PEGylated Au DENPs $(3.0 \mu \mathrm{M})$ for 24 hours at $37^{\circ} \mathrm{C}$. After washing, the cells were fixed and dehydrated using a graded ethanol series $(30 \%, 50 \%, 70 \%, 95 \%$, and $100 \%$ ) and embedded with Epon 812 (Shell Chemicals, Stanlow, UK). The embedded cells were then cut into $75 \mathrm{~nm}$ thick sections. After counterstaining with uranyl acetate and lead citrate for 5 minutes, the samples were photographed with a TEM (Hitachi Ltd., Tokyo, Japan) at the voltage of $60 \mathrm{kV}$.

\section{In vitro micro-CT imaging}

Ana-1 cells were grown in $25 \mathrm{~cm}^{2}$ flasks at a density of $3 \times 10^{6}$ cells/flask and incubated for 4 hours with FI-labeled PEGylated Au DENPs with 100 and $300 \mu \mathrm{M}$ Au at $37^{\circ} \mathrm{C}$. The control flasks were treated with RPMI 1640 medium alone. After washing, the cells were trypsinized and resuspended in a $0.5 \mathrm{~mL}$ Eppendorf tube containing approximately $5.0 \times 10^{6}$ Ana-1 cells. The cell pellets in each tube were scanned using a micro-CT (GE Healthcare Bio-Sciences Corp., Piscataway, NJ, USA) according to the manufacturer instructions.

\section{In vivo micro-CT imaging}

Animal experiments and animal care were in accordance with the protocols of Shanghai JiaoTong University School of Medicine. ApoE-KO (C57BL/6 background) mice and C57 mice were purchased from Shanghai Research Center for Model Organisms (Shanghai, People's Republic of China). Male ApoE-KO mice $(n=9)$ with a mean age of $11 \pm 1.6$ months were fed a Western diet (containing 21\% fat, $0.15 \%$ cholesterol) for at least 6 months before the experiment. The mice were anesthetized using an intraperitoneal dose of pentobarbital sodium $(40 \mathrm{mg} / \mathrm{kg})$. Au DENPs ( $0.4 \mu \mathrm{mol}$ Au per $\mathrm{g}$ body weight, $[\mathrm{Au}]=0.2 \mathrm{M})$ dispersed in PBS were then given intravenously into the mice tail veins. Age-matched C57 mice were used as the negative control $(n=3)$. All mice underwent a baseline scan at first, followed by micro-CT scans at 20 minutes and 2, 4, and 6 hours postinjection using a GE Healthcare imaging system. 


\section{Histologic staining}

The mice were euthanized after micro-CT imaging. The heart, lungs, stomach, spleen, liver, intestines, kidneys, testicles, blood, and brain were harvested, weighed, and cut into $1 \mathrm{~mm}^{3}$ to $2 \mathrm{~mm}^{3}$ pieces and immersed in aqua regia solution for 4 hours. The Au content was quantified by an inductively coupled plasma atomic emission spectroscopy (ICP-AES) system (Prodigy; Leeman, Hudson, NH, USA).

For histologic staining, the animals were anesthetized and perfusion-fixed after micro-CT scanning. The heart, lungs, liver, spleen, kidneys, intestines, and blood vessels were extracted and fixed in 4\% PFA. The organs were then dehydrated and embedded in paraffin. The samples were cut into $5 \mu \mathrm{m}$ sections, deparaffinized, and washed with PBS to obtain pretreatment sections.

For hematoxylin and eosin (HE) staining, the pretreated sections were washed and dipped into hematoxylin staining for 3-5 minutes. Subsequently, the sections were rinsed with distilled water for 10 minutes and stained with $1 \%$ eosin $Y$ solution for 2 minutes. Finally, the sections were dehydrated and observed through a Nikon optical microscope.

For silver staining, the pretreated sample sections were counterstained with a silver enhancement kit, and then washed with distilled water and stained with $1 \%$ nuclear fast red for 5 minutes. After washing thrice with PBS, the sections were air-dried, dehydrated, and mounted onto coverslips for light microscopy.

For immunohistochemical staining, the paraffin-embedded arteries and organ tissue sections were deparaffinized, washed, treated with $3 \%$ hydrogen peroxide for 15 minutes at $37^{\circ} \mathrm{C}$ to inactivate endogenous peroxidases, and washed thrice. The sections were then blocked for 30 minutes with $10 \%$ goat serum, and incubated for 2 hours with CD68 macrophage antibodies (rat monoclonal antibodies, 1:200) at $37^{\circ} \mathrm{C}$. After thorough washing thrice with PBS for 5 minutes, the samples were incubated with secondary biotinylated antibodies (goat anti-rat, $1: 200$ ) at $37^{\circ} \mathrm{C}$ for 45 minutes. The sections were washed and incubated for 15 minutes with ABC complex reagent. The sections were stained with 3,3'-diaminobenzidine and washed with PBS, and then counterstained for 5 minutes with hematoxylin. After being airdried and dehydrated, the sections were photographed under a light microscope. The sections were similarly incubated but without the primary antibodies as the negative control.

\section{Statistical analysis}

All of the quantitative data are expressed as means \pm standard deviation (SD). A paired $t$-test was applied to compare the differences between two groups using SPSS software (v16.0; IBM Corporation, Armonk, NY, USA). A one-way ANOVA was used to compare multiple groups, and significant differences were further analyzed through least significant difference (LSD). Differences with $P$-value $<0.05$ were considered statistically significant and labeled with $(*)$.

\section{Results and discussion Synthesis of Fl-labeled PEGylated Au DENPs}

Intravenous injection of PEGylated Au DENPs allows higher Au loading and effective blood pool imaging in mice. ${ }^{17}$ In this study, we conjugated FI to $\mathrm{G} 5 . \mathrm{NH}_{2}$ dendrimers, which have excellent fluorescence-labeling effects for in vivo biological tracking and CT imaging.

G5. $\mathrm{NH}_{2}$ dendrimers were modified successively with $m$ PEG-MAL and FI to produce G5. $\mathrm{NH}_{2}$-FI- $m$ PEG conjugates (Figure 1). The formed G5. $\mathrm{NH}_{2}-\mathrm{FI}-m \mathrm{PEG}$ were used as templates to synthesize $\left[\left(\mathrm{Au}^{0}\right)_{300}-\mathrm{G} 5 . \mathrm{NH}_{2}\right.$-FI-mPEG] DENPs, which were further acetylated to neutralize the dendrimer

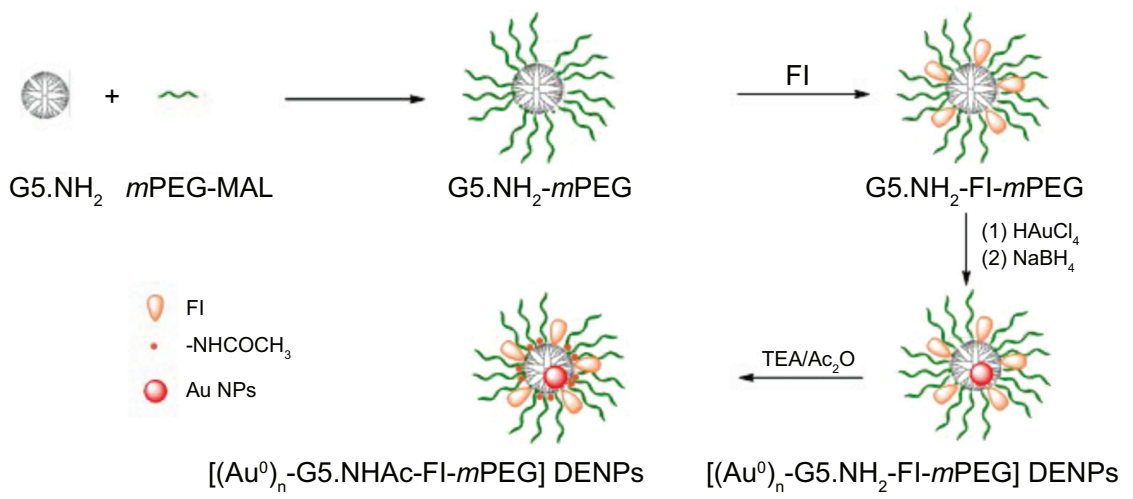

Figure I Schematic illustration of the preparation of $\left[\left(\mathrm{Au}^{0}\right)_{300^{-}}-\mathrm{G} 5 . \mathrm{NHAc}-\mathrm{FI}-\mathrm{mPEG}\right]$ DENPs.

Abbreviations: AuNPs, gold nanoparticles; DENP, dendrimer-entrapped gold nanoparticle; FI, fluorescein isothiocyanate; PEG, polyethylene glycol; TEA, triethanolamine. 
terminal amines (Figure 1). The obtained $\left[\left(\mathrm{Au}^{0}\right)_{300}-\mathrm{G} 5\right.$. NHAc-FI- $m$ PEG] DENPs were tested using ${ }^{1} \mathrm{H}$ nuclear magnetic resonance (NMR). The ${ }^{1} \mathrm{H}$ NMR spectrum of the $\left[\left(\mathrm{Au}^{0}\right)_{300}\right.$-G5.NHAc-FI-mPEG] DENPs is shown in Figure S1. The proton signal of the double bond in the benzene ring of FI (6.4 ppm to $6.7 \mathrm{ppm})$ indicated the successful nucleophilic addition of the dendrimer terminal amines (Figure 1). The $\left(-\mathrm{CH}_{2}-\mathrm{CH}_{2} \mathrm{O}-\right)$ protons at $3.6 \mathrm{ppm}$ and the $-\mathrm{COCH}_{3}$ protons at $1.87 \mathrm{ppm}$ are consistent with the results of our previous work on similarly synthesized Au DENPs..$^{14,17}$

The formation of $\left[\left(\mathrm{Au}^{0}\right)_{300}\right.$-G5.NHAc-FI- $m$ PEG] DENPs dispersed in water $(\mathrm{pH} 6.0)$ at $25^{\circ} \mathrm{C}$ was confirmed through UV-vis spectrometry (Figure $2 \mathrm{~A}$ ). The signal at around $500 \mathrm{~nm}$ to $510 \mathrm{~nm}$ was due to the overlap of the characteristic absorption peak of FI and the surface plasmon resonance peak of the AuNPs, which is in accordance with previous reports. ${ }^{17,23}$ The morphology and size of the formed $\left[\left(\mathrm{Au}^{0}\right)_{300}\right.$-G5.NHAc-FI- $m$ PEG] DENPs were also characterized by TEM. The TEM micrographs of the $\left[\left(\mathrm{Au}^{0}\right)_{300}-\mathrm{G} 5\right.$. NHAc-FI- $m$ PEG] DENPs are shown in Figure 2B. The size of the AuNPs at a given gold salt/dendrimer molar ratio was in a relatively narrow range (approximately $2-5 \mathrm{~nm}$ ), which suggests that the formation and growth of the AuNPs were effectively restricted within the G5. $\mathrm{NH}_{2}$-FI- $m$ PEG templates.

\section{Stability of $\left[\left(\mathrm{Au}^{0}\right)_{300}-\mathrm{G} 5 . \mathrm{NHAc}-\mathrm{Fl}-\mathrm{mPEG}\right]$ DENPs}

The stability of the $\left[\left(\mathrm{Au}^{0}\right)_{300}\right.$-G5.NHAc-FI- $m$ PEG] DENPs is prerequisite for their further biological applications. Data from the literature demonstrated that the changes in the absorption characteristics in the UV-vis spectrum effectively reflect the degree of AuNP aggregation. ${ }^{17}$ Therefore, the stability of $\left[\left(\mathrm{Au}^{0}\right)_{300}-\mathrm{G} 5 . \mathrm{NHAc}-\mathrm{FI}-m \mathrm{PEG}\right]$ DENPs under various $\mathrm{pH}$ and temperature conditions was analyzed through UV-vis spectrometry (Figure S2). The UV-vis spectra of the $\left[\left(\mathrm{Au}^{0}\right)_{300}\right.$-G5.NHAc-FI- $m$ PEG] DENPs dispersed in PBS with different $\mathrm{pH}$ values were studied at $25^{\circ} \mathrm{C}$ (Figure S2A). The spectra of all the $\left[\left(\mathrm{Au}^{0}\right)_{300}\right.$-G5.NHAc-FI-mPEG] DENPs did not significantly change at $\mathrm{pH}$ ranging from 5 to 8 , which suggests that PEGylated Au DENPs with different compositions are stable within the $\mathrm{pH}$ range.

The stability of the $\left[\left(\mathrm{Au}^{0}\right)_{300}\right.$-G5.NHAc-FI- $m$ PEG] DENPs dispersed in water $(\mathrm{pH} 7.0)$ at different temperatures $\left(4^{\circ} \mathrm{C}, 25^{\circ} \mathrm{C}, 37^{\circ} \mathrm{C}\right.$, and $\left.50^{\circ} \mathrm{C}\right)$ was similar to those with the same compositions at $25^{\circ} \mathrm{C}$ (Figure $\mathrm{S} 2 \mathrm{~B}$ ), which suggests that the $\left[\left(\mathrm{Au}^{0}\right)_{300}\right.$-G5.NHAc-FI- $m$ PEG] DENPs do not aggregate from $4^{\circ} \mathrm{C}$ to $50^{\circ} \mathrm{C}$. Thus, the $\left[\left(\mathrm{Au}^{0}\right)_{300}\right.$-G5.NHAc-FI- $m$ PEG $]$ DENPs are stable at different temperatures and $\mathrm{pH}$ conditions, which is crucial for their application as contrast agents in CT imaging. FI-labeled PEGylated dendrimers (G5. $\mathrm{NH}_{2}$-FI- $m$ PEG) also effectively have higher Au loading and exceptional colloidal stability even after the remaining dendrimer terminal amines were acetylated, which is mainly attributed to the expanded dendrimer periphery after partial PEGylation.

\section{Hemolytic assay of $\left[\left(\mathrm{Au}^{0}\right)_{300}-\mathrm{G} 5 . \mathrm{NHAc}-\mathrm{FI}-\right.$ $m$ PEG] DENPs}

Hemolytic assays are important for NPs designed for in vivo applications, especially if the NPs will come into contact with blood. The hemocompatibility of the $\left[\left(\mathrm{Au}^{0}\right)_{300}-\mathrm{G} 5\right.$. NHAc-FI- $m$ PEG] DENPs was tested as in our previous report. ${ }^{14}$ The hemolytic effect of the formed Au DENPs was investigated through measuring the absorbance of the supernatant at $577 \mathrm{~nm}$ after exposing the particles to a human
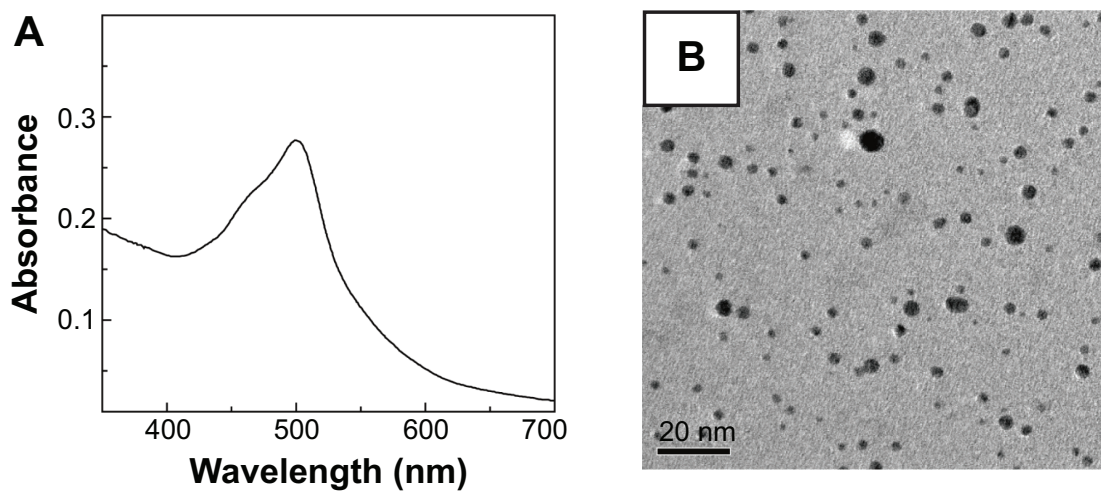

Figure 2 UV-vis spectra $(\mathbf{A})$ and TEM image $(\mathbf{B})$ of $\left[\left(\mathrm{Au}^{0}\right)_{300}\right.$-G5.NHAc-FI-mPEG] DENPs dispersed in water $(\mathrm{pH}=6.0)$ at room temperature $\left(25^{\circ} \mathrm{C}\right)$.

Abbreviations: DENP, dendrimer-entrapped gold nanoparticle; Fl, fluorescein isothiocyanate; PEG, polyethylene glycol; TEM, transmission electron microscopy; UV-vis, ultraviolet-visible. 
red blood cell (HRBC) suspension for 2 hours and centrifugation (Figure 3). The absorbance at $577 \mathrm{~nm}$ is attributed to the hemoglobin released by ruptured HRBCs (Figure 3A). Unlike the positive control (water), the formed Au DENPs induced lysis of less than 5\% of the HRBCs at 0-400 $\mu \mathrm{M}$ $\mathrm{Au}$ (Figure 3B). These results confirm the excellent hemocompatibility of the $\left[\left(\mathrm{Au}^{0}\right)_{300}\right.$-G5.NHAc-FI-mPEG] DENPs and the feasibility of using these NPs for in vivo blood CT imaging applications.

\section{Cytotoxicity of PEGylated Au DENPs}

A previous study debated whether increased intracellular Au DENPs induces lipid peroxidation and damages DNA, which may lead to cell apoptosis and death. ${ }^{25}$ Therefore, the cytotoxicity of the $\left[\left(\mathrm{Au}^{0}\right)_{300}\right.$-G5.NHAc-FI- $m$ PEG] DENPs was evaluated in vitro through a CCK-8 assay prior to their application in molecular CT imaging.

The CCK-8 assay showed that Ana-1 cells incubated with different Au concentrations (100-300 $\mu \mathrm{M})$ have similar cell viabilities (as high as 90\%) as the untreated control cells $(P>0.05, \mathrm{n}=4$; Figure 4$)$. Relative cell viability was only slightly affected up to an Au concentration of $400 \mu \mathrm{M}$ (Figure 4). The nontoxicity of the Au DENPs up to $300 \mu \mathrm{M}$ $\mathrm{Au}$ demonstrates that PEGylation modification greatly improves the biocompatibility of $\left[\left(\mathrm{Au}^{0}\right)_{300}\right.$-G5.NHAc-FI$m$ PEG] DENPs.

\section{Macrophage uptake of Fl-labeled PEGylated Au DENPs}

The $\left[\left(\mathrm{Au}^{0}\right)_{300}\right.$-G5.NHAc-FI-mPEG] DENPs must be phagocytosed by macrophages to prolong the CT imaging time of macrophages in atherosclerotic lesions. In vitro silver staining showed numerous dark granules in the cytoplasm of Ana-1 cells incubated for 4 hours with $\left[\left(\mathrm{Au}^{0}\right)_{300}-\mathrm{G} 5\right.$.NHAcFI- $m$ PEG] DENPs $([\mathrm{Au}]=100 \mu \mathrm{M}$ and $300 \mu \mathrm{M})$, which were darker at higher Au concentrations (Figures 5B and C). In contrast, no dark granules were detected in the negative control cells (Figure 5A). These results demonstrate that the Au DENPs effectively target macrophages.

Immunofluorescence double staining was used to verify the colocalization of $\left[\left(\mathrm{Au}^{0}\right)_{300}-\mathrm{G} 5\right.$.NHAc-FI- $m$ PEG $]$ DENPs with macrophages. As shown in Figure 6, the red-fluorescent Alexa Fluor ${ }^{\circledR}$ 555-labeled anti-F4/80, which specifically targets macrophages, ${ }^{26}$ were colocalized with the greenfluorescent FI-labeled Au DENPs. The colocalization areas of the $\left[\left(\mathrm{Au}^{0}\right)_{300}\right.$-G5.NHAc-FI-mPEG] DENPs and macrophages appeared yellow. Therefore, each FI-coated particle was associated with macrophages. By contrast, no green fluorescence was observed in the cytoplasm of the untreated control Ana-1 cells (data not shown). The FI fluorescence increased with increasing $\left[\left(\mathrm{Au}^{0}\right)_{300}\right.$-G5.NHAc-FI- $m$ PEG] DENP concentration, as shown in Figures 6A-D, demonstrating greater macrophage uptake of $\mathrm{Au}$ DENPs in accordance with the results of silver staining.

The murine macrophages treated with the $\left[\left(\mathrm{Au}^{0}\right)_{300}-\mathrm{G} 5\right.$. NHAc-FI- $m$ PEG] DENPs were observed under TEM to determine the distribution of the particles in the subcellular structures (Figure S3). After treatment with the $\left[\left(\mathrm{Au}^{0}\right)_{300}-\mathrm{G} 5\right.$. NHAc-FI- $m$ PEG] DENPs $([\mathrm{Au}]=300 \mu \mathrm{M})$ for 4 hours, numerous black particles were observed in the cytoplasm (Figure S3A), especially in the lysosomes (Figure S3B). The $\left[\left(\mathrm{Au}^{0}\right)_{300}-\mathrm{G} 5 . \mathrm{NHAc}-\mathrm{FI}-m \mathrm{PEG}\right] \mathrm{DENPs}$, in small aggregates, were inside vacuoles dispersed throughout the cytoplasm (red arrows). By contrast, no black particles were observed in the

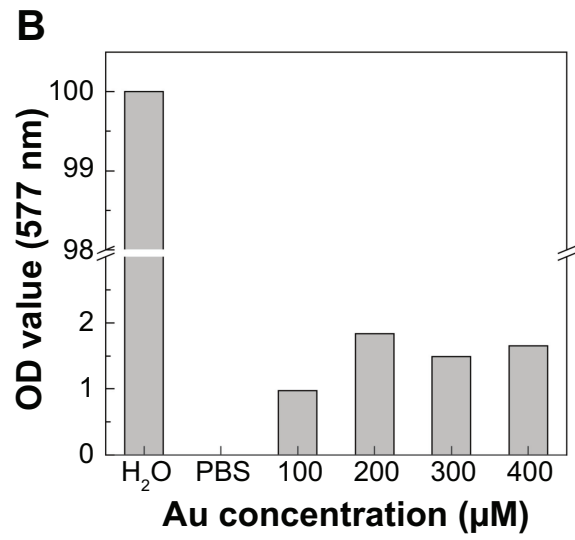

Figure 3 (A) UV-vis spectra of the HRBC suspensions treated with [( $\left.\mathrm{Au}^{0}\right)_{300}$-G5.NHAc-FI-mPEG] DENPs at different Au concentrations (I00 $\mu$ M [3], 200 $\mu$ M [4], $300 \mu M$ [5], and $400 \mu \mathrm{M}$ [6], respectively) and (B) hemolysis percentage of the Au DENPs as a function of the Au concentration.

Notes: In both (A) and (B), $\mathrm{H}_{2} \mathrm{O}(\mathrm{I})$ and PBS (2) were used as positive and negative control, respectively. Inset of (A) shows the enlarged UV-vis spectra of samples 2-6. Abbreviations: DENP, dendrimer-entrapped gold nanoparticle; Fl, fluorescein isothiocyanate; HRBC, human red blood cell; OD, optical density; PBS, phosphate-buffered solution; PEG, polyethylene glycol; UV-vis, ultraviolet-visible. 


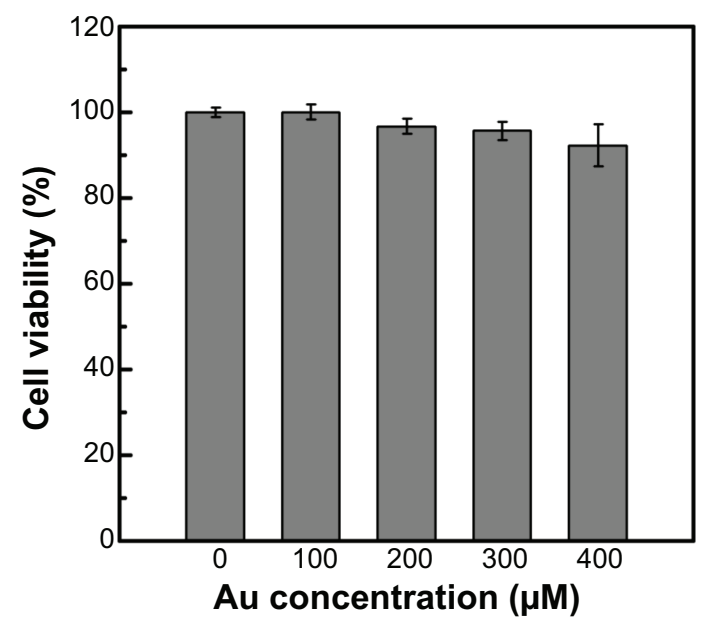

Figure 4 CCK-8 assay of the viability of macrophages treated with different $\left[\left(\mathrm{Au}^{0}\right)_{300}\right.$-G5.NHAc-Fl-mPEG] DENP concentrations for 24 hours $(\mathrm{n}=4)$. Abbreviations: CCK-8, cell counting kit-8; DENP, dendrimer-entrapped gold nanoparticle; Fl, fluorescein isothiocyanate; PEG, polyethylene glycol.

cytoplasm of the untreated Ana-1 cells (Figures S3C and D). The TEM results demonstrated that the $\left[\left(\mathrm{Au}^{0}\right)_{300}-\mathrm{G} 5\right.$.NHAcFI- $m$ PEG] DENPs were phagocytosed by the macrophages instead of adhering onto the cell surfaces. Furthermore, the TEM imaging analyses also confirm that incubating the $\left[\left(\mathrm{Au}^{0}\right)_{300}\right.$-G5.NHAc-FI- $m$ PEG] DENPs with Au concentrations as high as $300 \mu \mathrm{M}$ does not affect macrophage morphology, which is consistent with the CCK-8 cell viability assay results. The internalization of the NPs likely occurs through two distinct mechanisms: through phagocytosis and through endocytosis via cell membrane, which are consistent with previous reports. ${ }^{19}$

\section{In vitro micro-CT imaging of macrophages}

The good biocompatibility of the designed $\left[\left(\mathrm{Au}^{0}\right)_{300}-\mathrm{G} 5\right.$. NHAc-FI- $m$ PEG] DENPs inspired us to determine their potential as nanoprobes for the CT imaging of macrophages in vitro. After incubating the macrophage pellets with $\mathrm{Au}$ DENPs for 4 hours, they were subjected to a micro-CT (Figure S4A). The macrophage pellets incubated with $\mathrm{Au}$ DENPs were bright, whereas the control pellets incubated with RPMI 1640 media were indistinguishable from the background. The CT signal intensity was quantitatively analyzed to differentiate the brightness of the macrophages pellets treated with different Au concentrations (Figure S4). The CT values of the macrophage pellets treated with $100 \mu \mathrm{M}$ and $300 \mu \mathrm{M}$ Au were higher than those of the untreated control cells (Figure S4B). Furthermore, the Ana-1 cells incubated with $300 \mu \mathrm{M}$ (Au concentration) showed significantly higher X-ray attenuation than those treated with $100 \mu \mathrm{M}$ $\mathrm{Au}(P<0.05, \mathrm{n}=3)$. The $\mathrm{X}$-ray attenuation was directly proportional to the Au DENP concentration, which further demonstrates the potential of the $\left[\left(\mathrm{Au}^{0}\right)_{300}\right.$-G5.NHAc-FI$m$ PEG] DENPs as contrast agents for blood CT imaging of macrophages in AS.

\section{In vivo micro-CT imaging of atherosclerotic model}

To evaluate the availability of using $\left[\left(\mathrm{Au}^{0}\right)_{300}\right.$-G5.NHAcFI- $m$ PEG] DENPs for early AS imaging, the FI-labeled PEGylated Au DENPs were intravenously injected into ApoE-KO mice. The mice were established as AS mouse models, similar to human AS by feeding them a highcholesterol diet for 6 months. ${ }^{27,28}$ Age-matched wild-type C57 mice were used as the negative control group. Before $\mathrm{Au}$ DENP injection, all mice underwent a baseline CT scan for comparison, followed by scans at 20 minutes and 2, 4, and 6 hours postinjection. Representative micro-CT images of the ApoE-KO mice at the transectional, coronal, sagittal, and 3D planes are shown in Figure 7. The renal vein is indicated
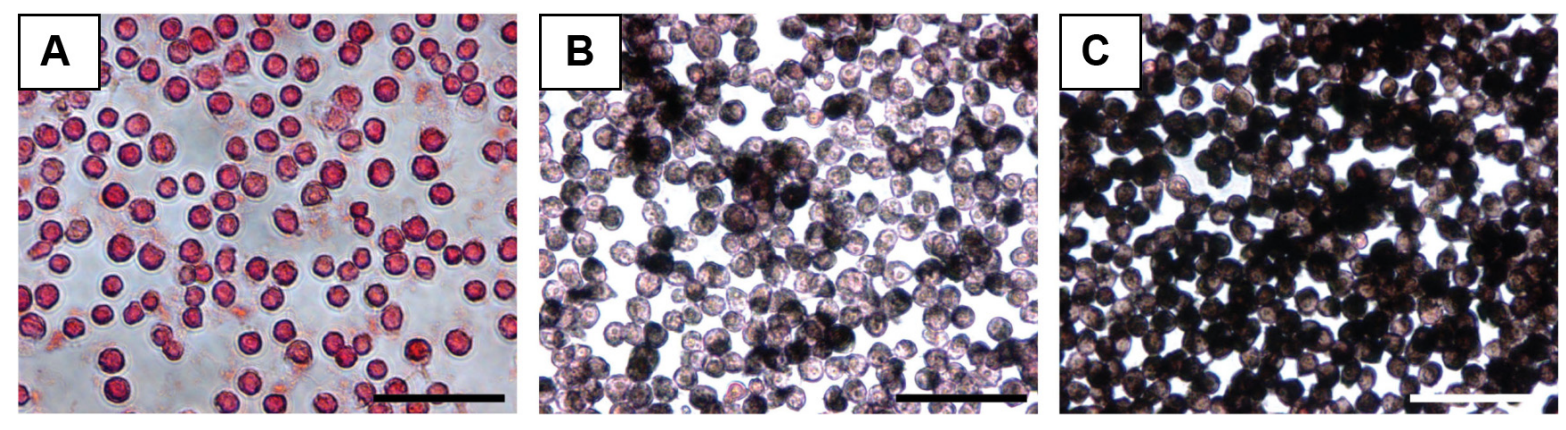

Figure 5 Representative microscope images of macrophages uptake of $\left[\left(\mathrm{Au}^{0}\right)_{300}-\mathrm{G} 5\right.$.NHAc-FI-mPEG] DENPs in vitro with silver staining: (A) negative control cells without treatment with PEGylated Au DENPs; the cells were incubated with $\left[\left(\mathrm{Au}^{0}\right)_{300}\right.$-G5.NHAc-FI-mPEG] DENPs (at the $[\mathrm{Au}]$ concentrations of I00 $\mu \mathrm{M}(\mathbf{B})$ and $300 \mu \mathrm{M}(\mathbf{C})$ for 4 hours).

Note: Scale bar measures $100 \mu \mathrm{m}$.

Abbreviations: DENP, dendrimer-entrapped gold nanoparticle; Fl, fluorescein isothiocyanate; PEG, polyethylene glycol. 

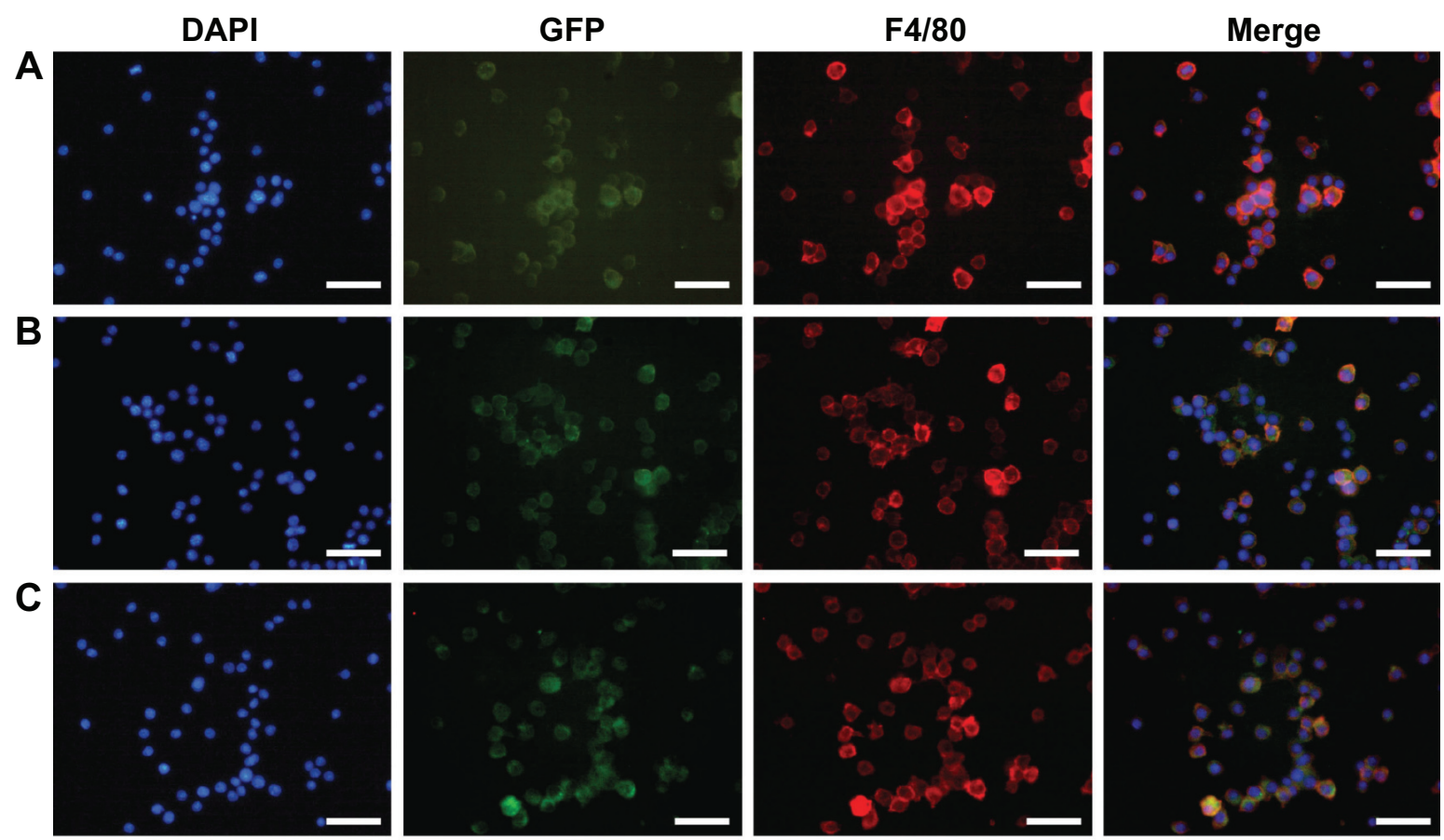

D
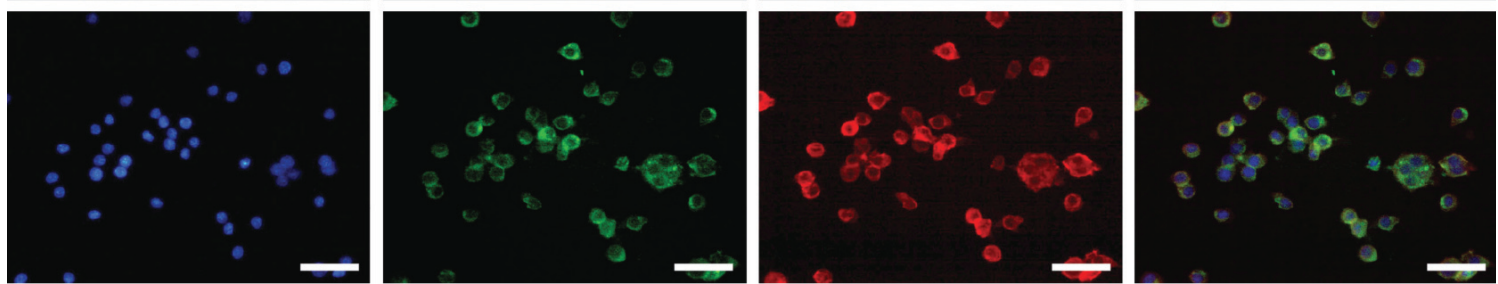

Figure 6 Representative immunofluorescence double staining images of F4/80 (red) and macrophages treated with [(Au $)_{300}{ }^{-G 5 . N H A c-F l-m P E G] ~ D E N P s ~}($ green) at the concentrations of (A) $1.0 \mu \mathrm{M}$, (B) $2.0 \mu \mathrm{M}$, (C) $3.0 \mu \mathrm{M}$, and (D) $4.0 \mu \mathrm{M}$ for 4 hours; the nuclei were stained with DAPI (blue).

Note: Scale bar measures $100 \mu \mathrm{m}$.

Abbreviations: DAPI, 4',6-diamidino-2-phenylindole; DENP, dendrimer-entrapped gold nanoparticle; FI, fluorescein isothiocyanate; GFP, green fluorescent protein; PEG, polyethylene glycol.

by a white arrow (Figure 7A), the inferior vena cava by a yellow arrow (Figures 7A-C), and the pulmonary artery by a red arrow (Figure 7D). In the sagittal plane (Figure 7B) and the coronal plane (Figure 7C) of the micro-CT image, the yellow arrow indicates the inferior vena cava, which can be clearly distinguished in the micro-CT images. In addition, the liver regions of mice were also easily discerned at 2, 4, and 6 hours postadministration of PEGylated Au DENPs in the reconstructed 3D CT images (Figures 7E and F). Our results demonstrate that modification of Au DENPs with PEG molecules can prolong the blood circulation time in ApoE-KO mice.

Mice injected with the $\left[\left(\mathrm{Au}^{0}\right)_{300}\right.$-G5.NHAc-FI-mPEG] DENPs exhibited significantly higher CT values compared with untreated mice (Figure S5). Moreover, the Au DENPs diffused into entire vessels and the atherosclerotic vessel regions gradually became clearer after injection. The CT values of the atherosclerotic vessels remained significantly higher than that of the areas before injection until 6 hours postinjection. No significant difference was observed between the muscles and the vessel walls in regions devoid of macrophages, as confirmed through histopathology (Figure 8). $\left[\left(\mathrm{Au}^{0}\right)_{300}\right.$-G5.NHAc-FI- $m$ PEG] DENPs at $300 \mu \mathrm{M}$ significantly enhanced the $\mathrm{CT}$ values compared with the areas before injection (Figure S5), which suggests that the macrophages may take up the $\left[\left(\mathrm{Au}^{0}\right)_{300}-\mathrm{G} 5\right.$.NHAc-FI- $m$ PEG] DENPs, as in previous reports. ${ }^{29,30}$

\section{In vivo biodistribution of} $\left[\left(\mathrm{Au}^{0}\right)_{300}-\mathrm{G} 5\right.$. NHAc-FI-mPEG] DENPs for atherosclerotic model

The biodistribution of the $\left[\left(\mathrm{Au}^{0}\right)_{300}\right.$-G5.NHAc-FI- $m$ PEG] DENPs at 6 hours postinjection was also determined through ICP-AES to quantify the Au concentration in the major 


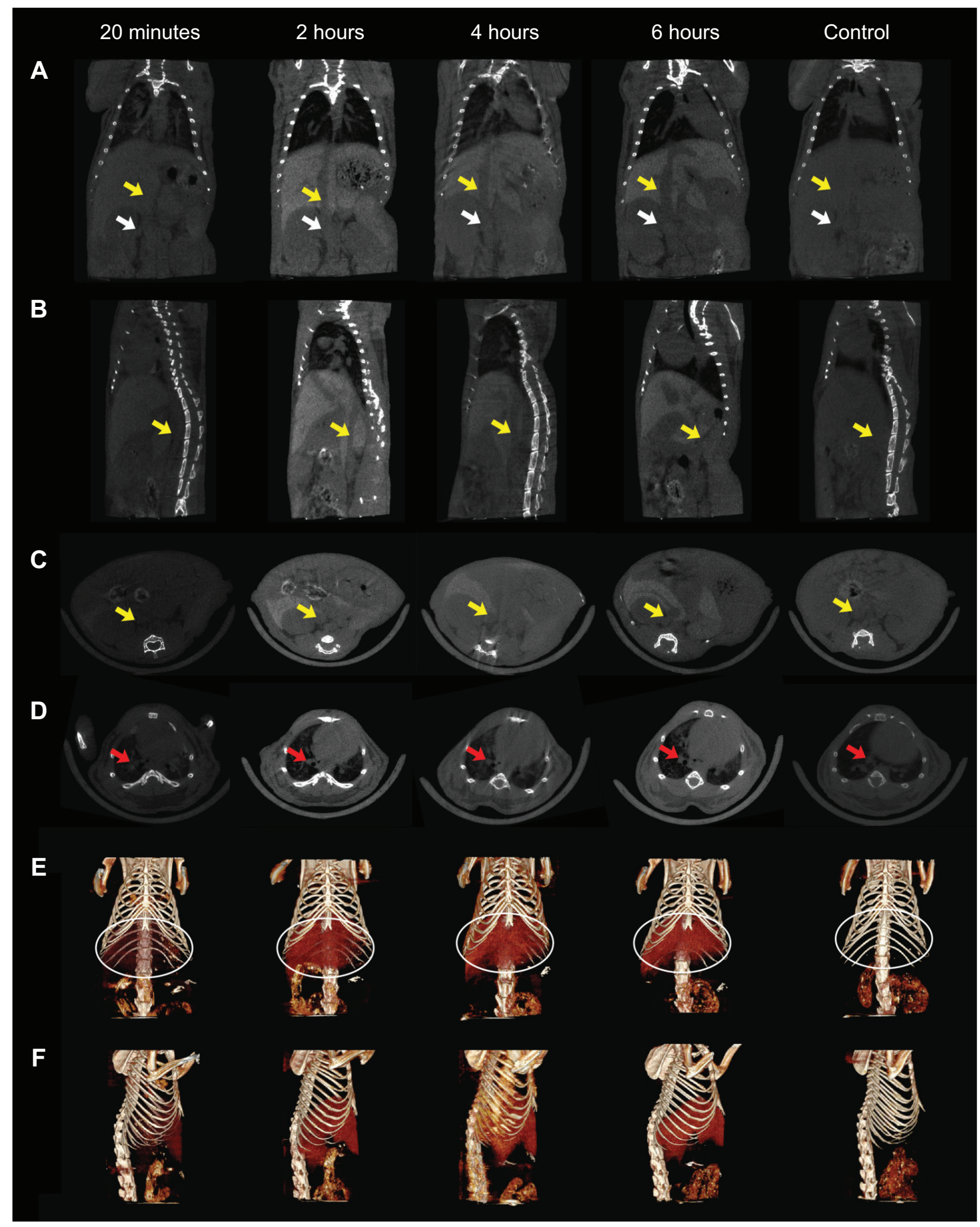

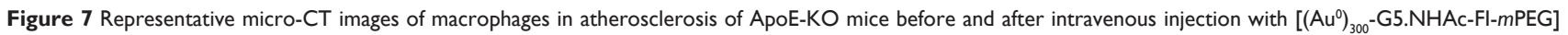
DENPs for 20 minutes and 2, 4, and 6 hours.

Notes: (A) coronal plane, (B) sagittal plane, (C, D) transversal planes, and the corresponding 3D renderings of in vivo CT images (E, F). The yellow, white, and the red arrows point to the inferior vena cava vein, the renal vein, and the pulmonary vein of the mouse, respectively.

Abbreviations: ApoE-KO, apolipoprotein E knockout; CT, computed tomography; DENP, dendrimer-entrapped gold nanoparticle; Fl, fluorescein isothiocyanate; PEG, polyethylene glycol. 

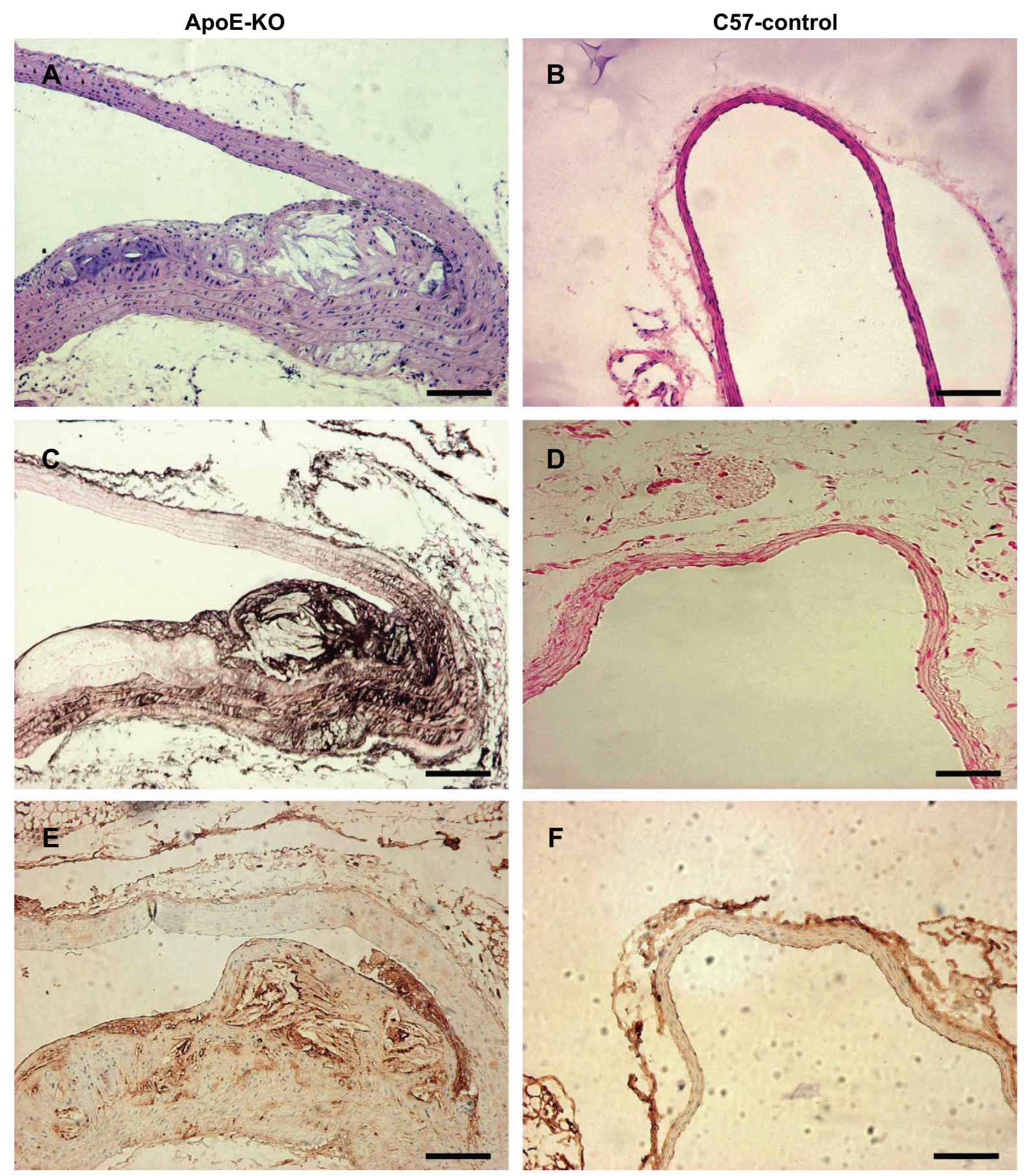

Figure 8 Representative HE staining, silver staining, and CD68 staining of arteries in ApoE-KO mice and $\mathrm{C57}$ control mice after intravenous injection with $\left[\left(\mathrm{Au}^{\circ}\right)_{300^{\circ}}-\mathrm{G} 5\right.$. NHAc-Fl-mPEG] DENPs for 6 hours.

Notes: (A, B) HE staining; (C, D) silver staining; (E, F) immunohistochemistry for macrophages stained with a monoclonal antibody CD68. Scale bar measures $100 \mu \mathrm{m}$. Abbreviations: ApoE-KO, apolipoprotein E knockout; DENP, dendrimer-entrapped gold nanoparticle; Fl, fluorescein isothiocyanate; HE, hematoxylin and eosin; PEG, polyethylene glycol.

organs such as the heart, lungs, stomach, spleen, liver, intestines, kidneys, testicles, blood, and brain (Figure S6). As shown in Figure S6, the liver had the highest Au uptake. The longer half-life of the PEGylated Au DENPs compared with the AuNPs (12.5 hours) reported in our previous study ${ }^{17}$ suggests that PEGylation of Au DENPs prolongs their retention time in the blood, which is essential for application in both blood pool CT imaging and AS CT imaging via enhanced permeability and retention effect. Detailed pharmacokinetic investigations of the $\left[\left(\mathrm{Au}^{0}\right)_{300}\right.$-G5.NHAc-FI-mPEG] DENPs at longer periods are necessary to determine their long-term biodistribution. 

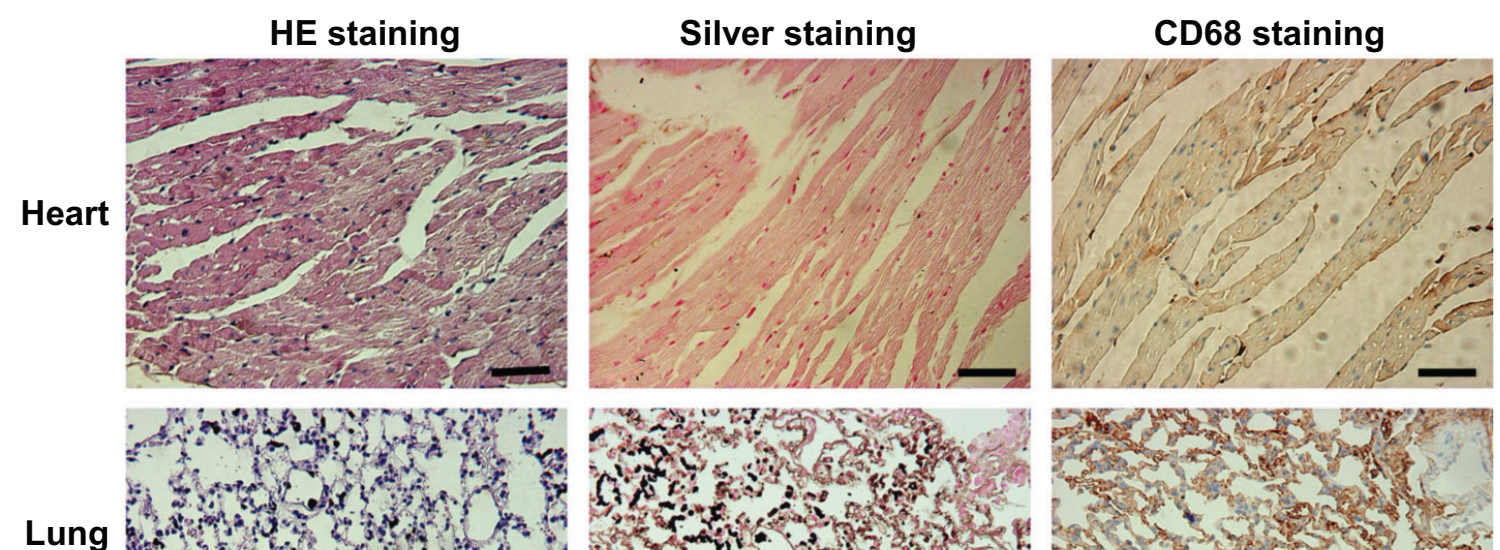

Lung a d th
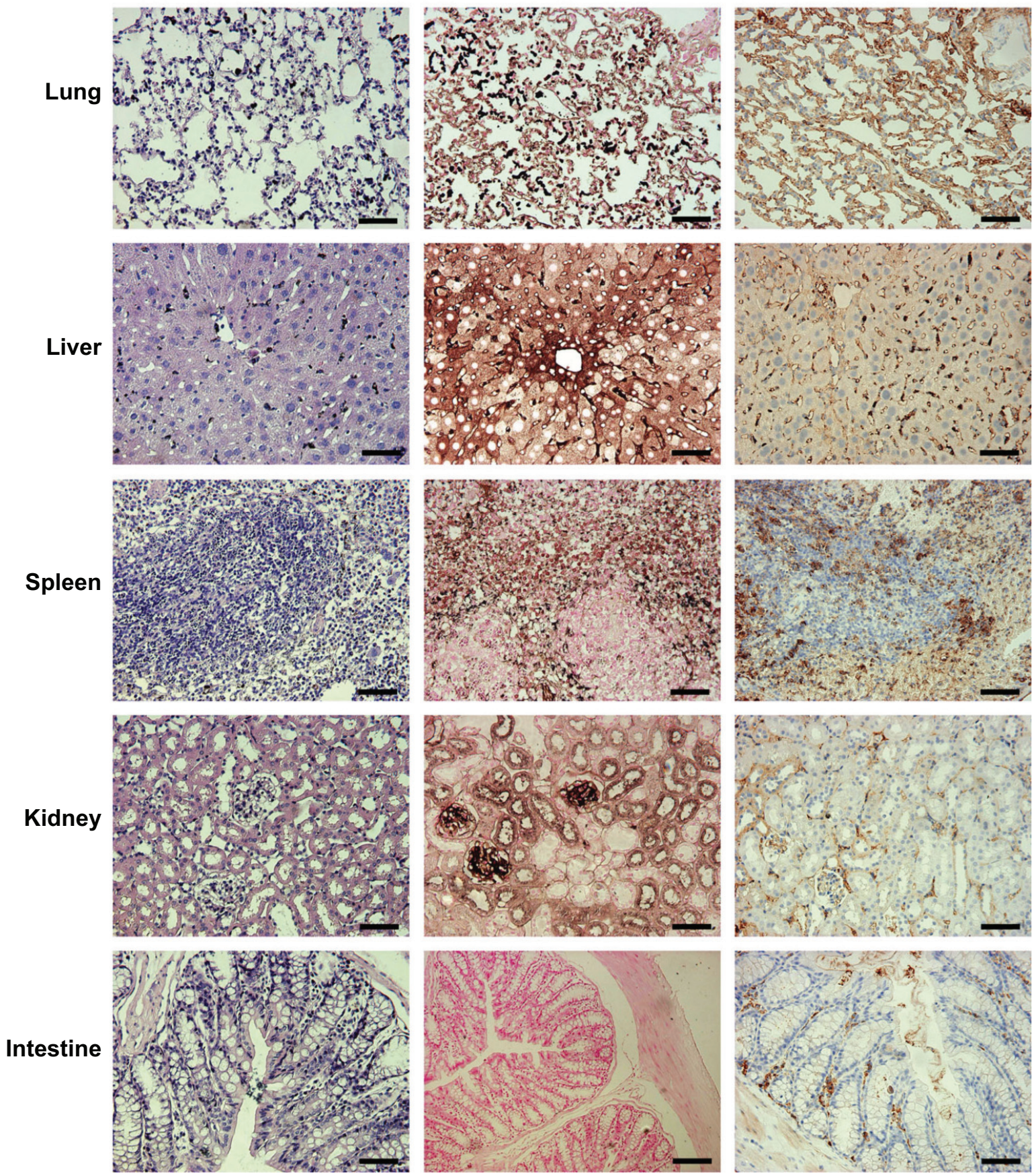

Figure 9 Representative images of $\mathrm{HE}$ staining, silver staining, and $\mathrm{CD} 68$ staining of main visceral organs in $\mathrm{ApoE}-\mathrm{KO}$ mice after intravenous injection with $\left[\left(\mathrm{Au}^{0}\right)_{300}-\mathrm{G} 5\right.$ NHAc-FI-mPEG] DENPs for 6 hours.

Note: Scale bar measures $100 \mu \mathrm{m}$.

Abbreviations: ApoE-KO, apolipoprotein E knockout; DENP, dendrimer-entrapped gold nanoparticle; Fl, fluorescein isothiocyanate; HE, hematoxylin and eosin; PEG, polyethylene glycol. 


\section{Histologic staining}

The arteries and major organs of the ApoE-KO mice were subjected to HE staining, silver staining, and immunohistochemical staining and observed at 6 hours after intravenous $\left[\left(\mathrm{Au}^{0}\right)_{300}\right.$-G5.NHAc-FI- $m$ PEG] DENPs injection to examine its metabolism and distribution. By HE staining, the atherosclerotic arteries in Apo E-KO mice (Figure 8A) showed the atheroma with large necrotic core, thin fibrous cap, and abundant macrophages compared with C57 control mice (Figure 8B). The atherosclerotic arteries were also stained with silver to verify whether the $\left[\left(\mathrm{Au}^{0}\right)_{300}\right.$-G5.NHAc-FI- $m$ PEG] DENPs were phagocytosed by the macrophages in atherosclerotic sites. Figure $8 \mathrm{C}$ shows numerous black spots in the atherosclerotic atheroma, which suggest the presence of AuNPs. By contrast, no black spots were observed in the negative control group (Figure 8D).

To investigate whether the macrophages in atherosclerotic arteries preferentially took up the $\left[\left(\mathrm{Au}^{0}\right)_{300}\right.$-G5.NHAc-FI$m$ PEG] DENPs, the macrophage-specific marker CD68 was used in immunohistochemical staining of the aorta and major organs. The black spots from silver staining in the atherosclerotic arteries were significantly correlated with the intensity of macrophage infiltration in the atherosclerotic arteries (Figures $8 \mathrm{C}$ and E). At 6 hours after injection, all Au-containing cells were positive for CD68 staining (Figure 8E), which further confirms that the $\left[\left(\mathrm{Au}^{0}\right)_{300}\right.$-G5.NHAc-FI- $m$ PEG] DENPs were taken up by the macrophages. In contrast, the macrophages in the control groups did not take up the $\left[\left(\mathrm{Au}^{0}\right)_{300}\right.$-G5.NHAc-FI- $m$ PEG] DENPs (Figures $8 \mathrm{D}$ and $\mathrm{F}$ ). This result is consistent with earlier studies wherein molecular probes were used to detect and assess macrophages in atherosclerotic lesions through magnetic resonance imaging. ${ }^{30,31}$ At 6 hours postinjection, small amounts of Au were still present in the spleen, liver, lungs, and kidneys, but no Au was observed in the heart and intestines (Figure 9). This result implies that the metabolic rates in the heart and intestines were higher than in the spleen, liver, lungs, and kidneys.

\section{Conclusion}

In summary, Au DENPs with PEG and FI coatings were synthesized, characterized, and investigated in murine macrophages. The CCK-8 cell viability analyses show that PEGylated Au DENPs are noncytotoxic up to $300 \mu \mathrm{M} \mathrm{Au}$. The morphology and localization of $\left[\left(\mathrm{Au}^{0}\right)_{300}\right.$-G5.NHAcFI- $m$ PEG] DENPs were examined through silver staining, fluorescence microscopy, and TEM. We demonstrated that macrophage recruitment to atherosclerotic lesions could be visualized noninvasively and dynamically in live animals using micro-CT. Moreover, considering the unique structural characteristics of the Au DENPs that can be further modified with various targeting ligands (eg, antibodies, folic acid, and Arg-Gly-Asp peptide), the designed PEGylated Au DENPs are a promising biocompatible contrast agent for $\mathrm{CT}$ imaging macrophages in atherosclerotic lesions and will provide new insights into the pathophysiology of AS and other inflammatory diseases.

\section{Acknowledgments}

This research is financially supported by the National Natural Science Foundation of China (81370423, 81371517, and 81401458), the Shanghai JiaoTong University School of Medicine Doctoral Innovation foundation (BXJ201231, for J Qin), and the Fund of the Science and Technology Commission of Shanghai Municipality (Grant no. 134119a2100, 14ZR1432400, and 124119a4900).

\section{Disclosure}

The authors report no conflicts of interest in this work.

\section{References}

1. Bhatt DL, Eagle KA, Ohman EM, et al; REACH Registry Investigators. Comparative determinants of 4-year cardiovascular event rates in stable outpatients at risk of or with atherothrombosis. JAMA. 2010;304(12):1350-1357.

2. Elias-Smale SE, Wieberdink RG, Odink AE, et al. Burden of atherosclerosis improves the prediction of coronary heart disease but not cerebrovascular events: the Rotterdam Study. Eur Heart J. 2011;32(16):2050-2058.

3. Libby P, Ridker PM, Hansson GK. Progress and challenges in translating the biology of atherosclerosis. Nature. 2011;473(7347):317-325.

4. Weber C, Noels H. Atherosclerosis: current pathogenesis and therapeutic options. Nat Med. 2011;17(11):1410-1422.

5. Hristov M, Weber C. Differential role of monocyte subsets in atherosclerosis. Thromb Haemost. 2011;106(5):757-762.

6. Murray PJ, Wynn TA. Protective and pathogenic functions of macrophage subsets. Nat Rev Immunol. 2011;11(11):723-737.

7. Potteaux S, Gautier EL, Hutchison SB, et al. Suppressed monocyte recruitment drives macrophage removal from atherosclerotic plaques of Apoe-/- mice during disease regression. J Clin Invest. 2011;121(5):2025-2036.

8. Dahl TB, Yndestad A, Skjelland M, et al. Increased expression of visfatin in macrophages of human unstable carotid and coronary atherosclerosis: possible role in inflammation and plaque destabilization. Circulation. 2007;115(8):972-980.

9. Jokerst JV, Gambhir SS. Molecular imaging with theranostic nanoparticles. Acc Chem Res. 2011;44(10):1050-1060.

10. Chen IY, Wu JC. Cardiovascular molecular imaging: focus on clinical translation. Circulation. 2011;123(4):425-443.

11. Quillard T, Libby P. Molecular imaging of atherosclerosis for improving diagnostic and therapeutic development. Circ Res. 2012; 111(2):231-244.

12. Bamberg F, Sommer WH, Hoffmann V, et al. Meta-analysis and systematic review of the long-term predictive value of assessment of coronary atherosclerosis by contrast-enhanced coronary computed tomography angiography. J Am Coll Cardiol. 2011;57(24):2426-2436. 
13. Chow BJ, Wells GA, Chen L, et al. Prognostic value of 64-slice cardiac computed tomography severity of coronary artery disease, coronary atherosclerosis, and left ventricular ejection fraction. $J \mathrm{Am}$ Coll Cardiol. 2010;55(10):1017-1028.

14. Peng C, Li K, Cao X, et al. Facile formation of dendrimer-stabilized gold nanoparticles modified with diatrizoic acid for enhanced computed tomography imaging applications. Nanoscale. 2012; 4(21):6768-6778.

15. Wang H, Zheng L, Peng C, et al. Computed tomography imaging of cancer cells using acetylated dendrimer-entrapped gold nanoparticles. Biomaterials. 2011;32(11):2979-2988.

16. Galper MW, Saung MT, Fuster V, et al. Effect of computed tomography scanning parameters on gold nanoparticle and iodine contrast. Invest Radiol. 2012;47(8):475-481.

17. Peng $\mathrm{C}$, Zheng L, Chen Q, et al. PEGylated dendrimer-entrapped gold nanoparticles for in vivo blood pool and tumor imaging by computed tomography. Biomaterials. 2012;33(4):1107-1119.

18. Vekilov PG. Gold nanoparticles: Grown in a crystal. Nat Nanotechnol. 2011;6(2):82-83.

19. Basu S, Mukherjee B, Chowdhury SR, et al. Colloidal gold-loaded, biodegradable, polymer-based stavudine nanoparticle uptake by macrophages: an in vitro study. Int J Nanomedicine. 2012;7:6049-6061.

20. Ando J, Fujita K, Smith NI, Kawata S. Dynamic SERS imaging of cellular transport pathways with endocytosed gold nanoparticles. Nano Lett. 2011;11(12):5344-5348.

21. Khlebtsov N, Dykman L. Biodistribution and toxicity of engineered gold nanoparticles: a review of in vitro and in vivo studies. Chem Soc Rev. 2011;40(3):1647-1671.

22. Cai QY, Kim SH, Choi KS, et al. Colloidal gold nanoparticles as a blood-pool contrast agent for X-ray computed tomography in mice. Invest Radiol. 2007;42(12):797-806.
23. Shi X, Wang SH, Meshinchi S, et al. Dendrimer-entrapped gold nanoparticles as a platform for cancer-cell targeting and Imaging. Small. 2007;3(7):1245-1252.

24. Qin J, Li K, Peng C, et al. MRI of iron oxide nanoparticle-labeled ADSCs in a model of hindlimb ischemia. Biomaterials. 2013; 34(21):4914-4925.

25. Kolodgie FD, Petrov A, Virmani R, et al. Targeting of apoptotic macrophages and experimental atheroma with radiolabeled annexin $\mathrm{V}$ : a technique with potential for noninvasive imaging of vulnerable plaque. Circulation. 2003;108(25):3134-3139.

26. Lin HH, Stacey M, Stein-Streilein J, Gordon S. F4/80: the macrophagespecific adhesion-GPCR and its role in immunoregulation. Adv Exp Med Biol. 2010;706:149-156.

27. Eriksson EE. Intravital microscopy on atherosclerosis in apolipoprotein e-deficient mice establishes microvessels as major entry pathways for leukocytes to advanced lesions. Circulation. 2011;124(19):2129-2138.

28. Weber C, Soehnlein O. ApoE controls the interface linking lipids and inflammation in atherosclerosis. J Clin Invest. 2011;121(10): 3825-3827.

29. McCarthy JR, Korngold E, Weissleder R, Jaffer FA. A light-activated theranostic nanoagent for targeted macrophage ablation in inflammatory atherosclerosis. Small. 2010;6(18):2041-2049.

30. Briley-Saebo KC, Shaw PX, Mulder WJ, et al. Targeted molecular probes for imaging atherosclerotic lesions with magnetic resonance using antibodies that recognize oxidation-specific epitopes. Circulation. 2008;117(25):3206-3215.

31. Amirbekian V, Lipinski MJ, Briley-Saebo KC, et al. Detecting and assessing macrophages in vivo to evaluate atherosclerosis noninvasively using molecular MRI. Proc Natl Acad Sci U S A. 2007;104(3): 961-966. 


\section{Supplementary materials}

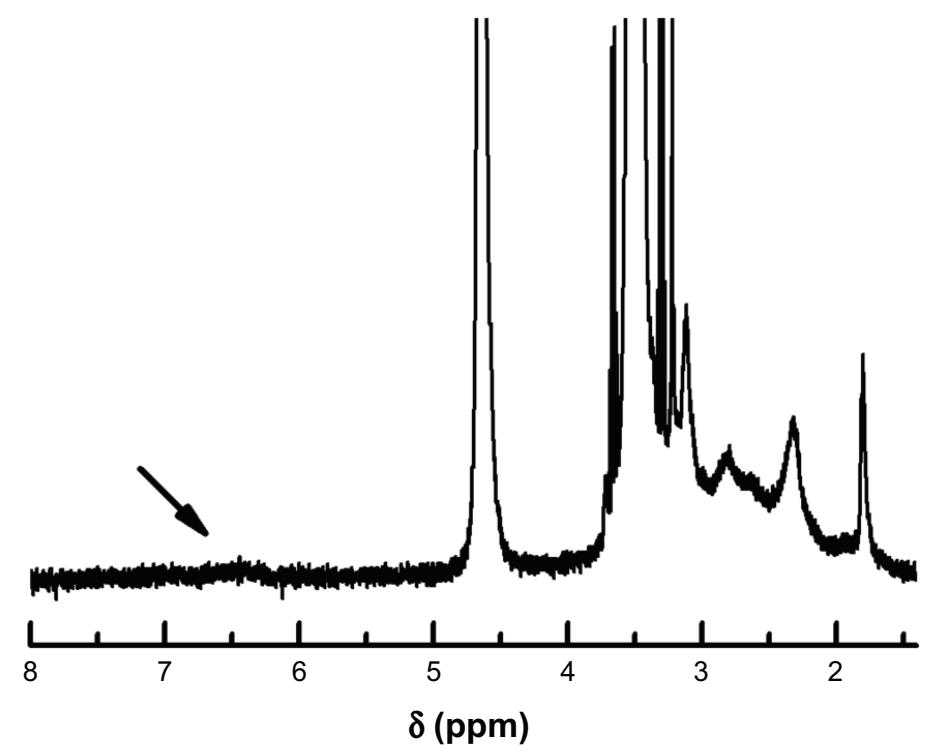

Figure SI 'H NMR spectra of $\left[\left(\mathrm{Au}^{\circ}\right)_{300}{ }^{-G 5}\right.$.NHAc-Fl-mPEG] DENPs $\left(\mathrm{D}_{2} \mathrm{O}\right)$.

Note: The arrow indicates the proton signal of the double bond in the benzene ring of FI (6.4 ppm to $6.7 \mathrm{ppm}$ ) indicating the successful nucleophilic addition of the dendrimer terminal amines.
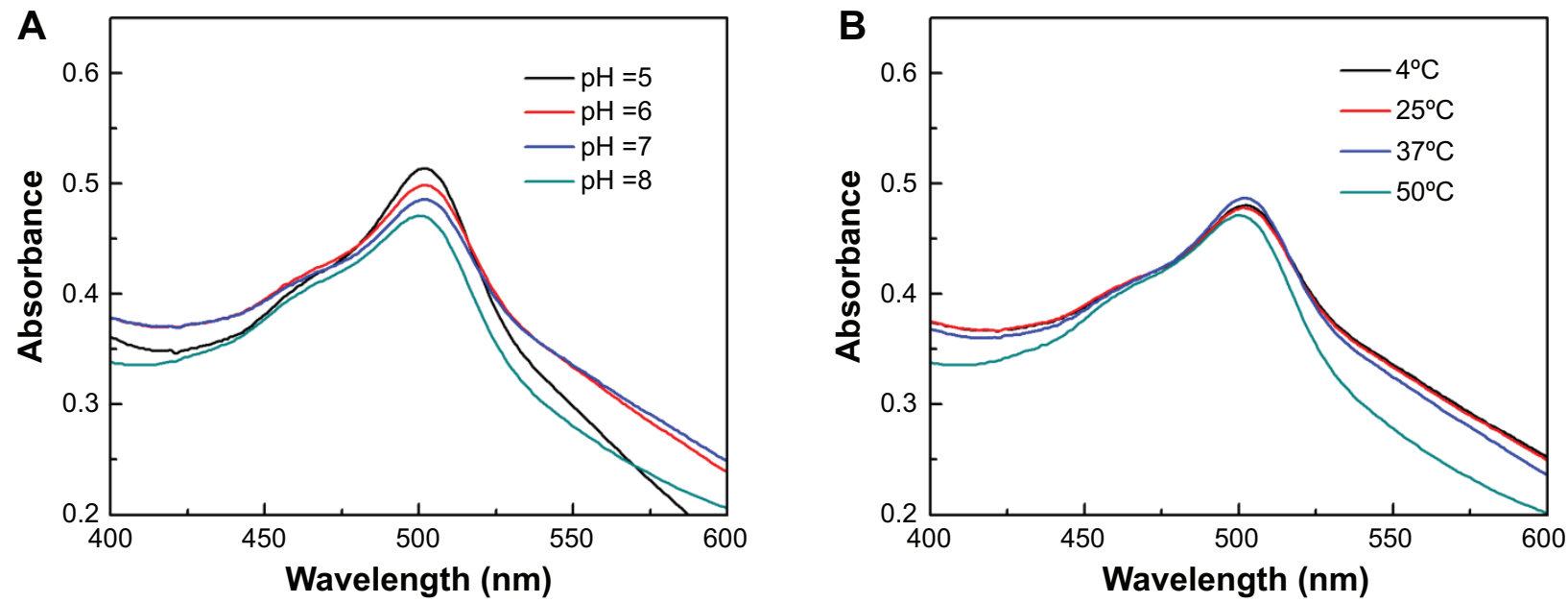

Figure S2 UV-vis spectra of $\left[\left(\mathrm{Au}^{0}\right)_{30}-\mathrm{G} 5\right.$.NHAc-FI-mPEG] DENPs dispersed in $(\mathbf{A})$ phosphate buffer $(\mathrm{pH}=5-8)$ at room temperature $\left(25^{\circ} \mathrm{C}\right)$ and $(\mathbf{B})$ in water solution $(\mathrm{pH}=7.0)$ at different temperatures $\left(4^{\circ} \mathrm{C}-50^{\circ} \mathrm{C}\right)$.

Abbreviations: DENP, dendrimer-entrapped gold nanoparticle; FI, fluorescein isothiocyanate; PEG, polyethylene glycol; UV-vis, ultraviolet-visible. 

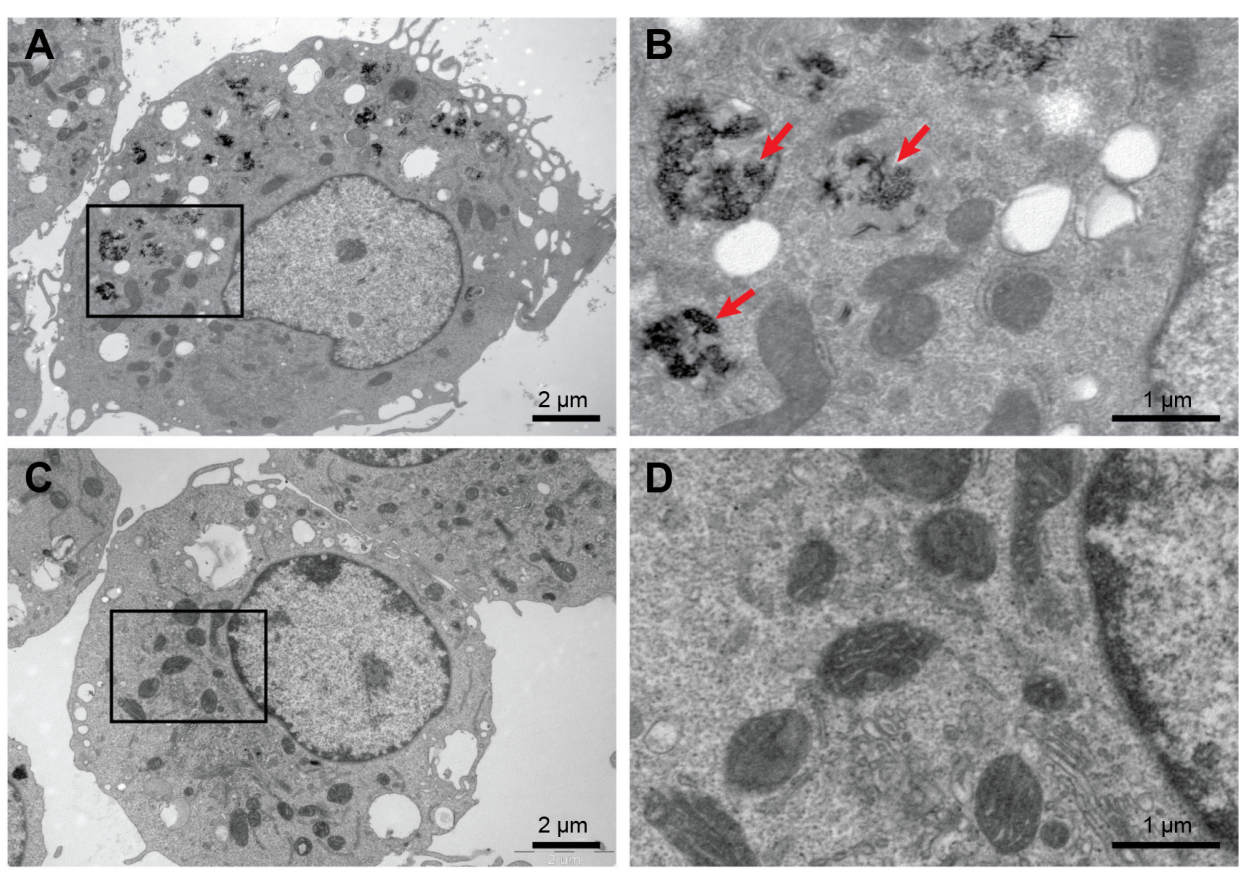

Figure S3 TEM images of macrophages.

Notes: (A) cells incubated with $\left[\left(\mathrm{Au}^{0}\right)_{30}\right.$-G5.NHAc-Fl-mPEG] DENPs at the Au concentration of $300 \mu \mathrm{M}$ for 4 hours; (B) magnified view of the square area in (A) - the red arrows in (B) show the AuNPs located at the lysosomes; (C) negative control cells without treatment; (D) magnified view of the square area in (C).

Abbreviations: AuNPs, gold nanoparticles; DENP, dendrimer-entrapped gold nanoparticle; Fl, fluorescein isothiocyanate; PEG, polyethylene glycol; TEM, transmission electron microscopy.

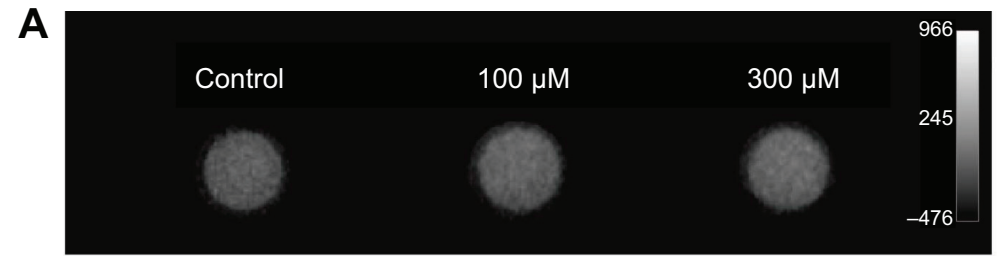

B

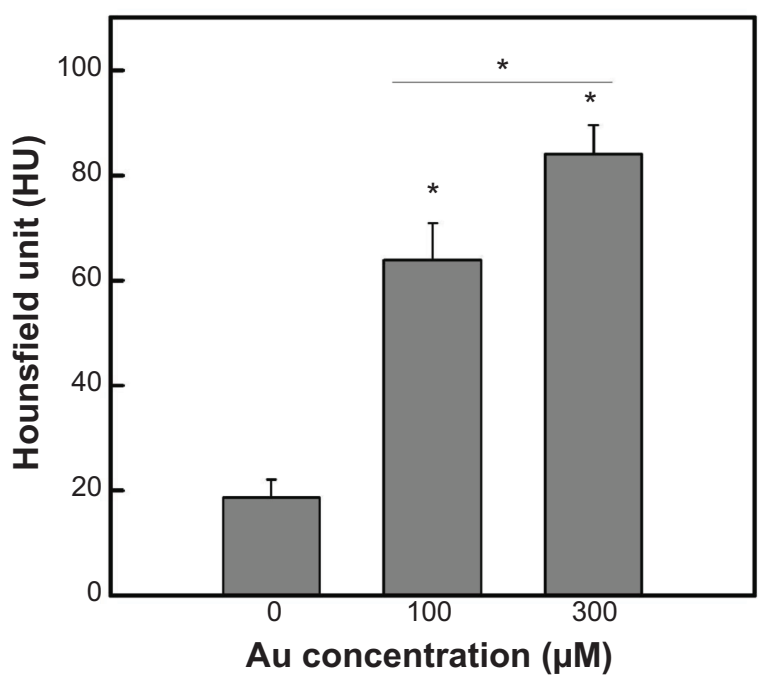

Figure S4 (A) Representative in vitro transverse micro-CT images of the macrophage pellets incubated with $\left[\left(\mathrm{Au}^{0}\right)_{300^{-}} \mathrm{G5}\right.$.NHAc-Fl-mPEG] DENPs with different Au concentrations for 4 hours and (B) the CT values of the macrophage pellets incubated with different concentrations of $A u(n=3)$. *There are significant differences among the three groups.

Abbreviations: CT, computed tomography; DENP, dendrimer-entrapped gold nanoparticle; Fl, fluorescein isothiocyanate; PEG, polyethylene glycol. 


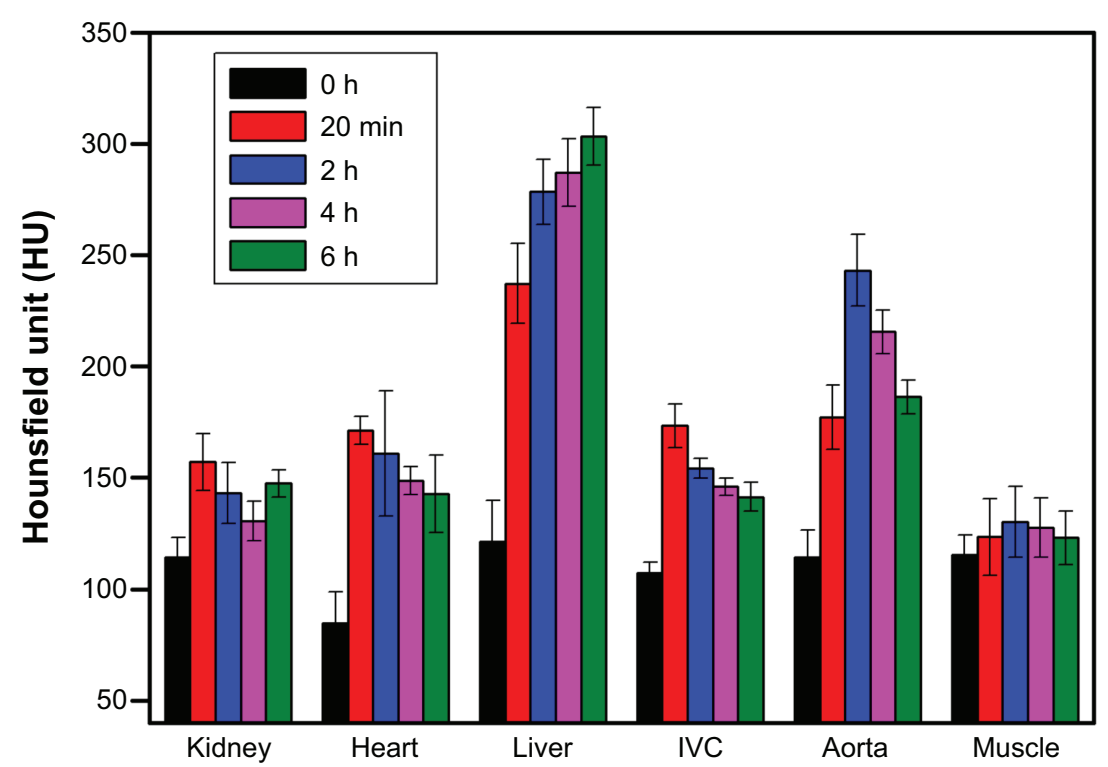

Figure S5 The CT values $(\mathrm{HU})$ of different organs before injection and at 20 minutes and 2, 4, and 6 hours after intravenous injection of $\left[\left(\mathrm{Au}^{0}\right)_{300}{ }^{-\mathrm{G} 5} 5 . \mathrm{NHAc}-\mathrm{Fl}-\mathrm{mPEG}\right]$ DENPs.

Abbreviations: CT, computed tomography; DENP, dendrimer-entrapped gold nanoparticle; FI, fluorescein isothiocyanate; IVC, inferior vena cava; PEG, polyethylene glycol.

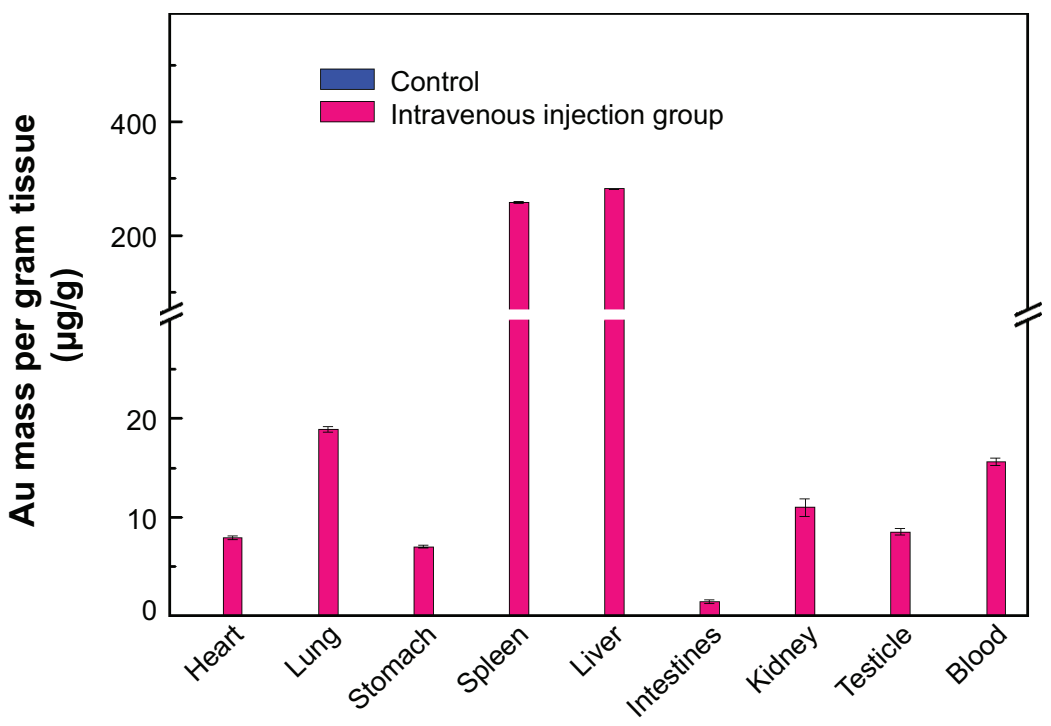

Figure S6 The biodistribution of $\left[\left(\mathrm{Au}^{0}\right)_{300}-\mathrm{G} 5 . \mathrm{NHAc}-\mathrm{FI}-\mathrm{mPEG}\right]$ DENPs in different organs.

Note: The data were obtained by ICP-AES at 6 hours postinjection in ApoE-KO mice models.

Abbreviations: ApoE-KO, apolipoprotein E knockout; DENP, dendrimer-entrapped gold nanoparticle; FI, fluorescein isothiocyanate; ICP-AES, inductively coupled plasma atomic emission spectroscopy; PEG, polyethylene glycol.

\section{Publish your work in this journal}

The International Journal of Nanomedicine is an international, peerreviewed journal focusing on the application of nanotechnology in diagnostics, therapeutics, and drug delivery systems throughout the biomedical field. This journal is indexed on PubMed Central, MedLine, CAS, SciSearch $®$, Current Contents ${ }^{\circledR} /$ Clinical Medicine,
Journal Citation Reports/Science Edition, EMBase, Scopus and the Elsevier Bibliographic databases. The manuscript management system is completely online and includes a very quick and fair peer-review system, which is all easy to use. Visit http://www.dovepress.com/ testimonials.php to read real quotes from published authors. 